\title{
Raise the Bar for Family Medicine Residencies
}

Joe Skariah, DO; John Saultz, MD

(Fam Med. 2022;54(2):89-90.)

doi: 10.22454/FamMed.2022.260316

$\mathbf{F}$ ebruary is an anxious time for residency programs as we prepare match lists and hope for results that will bring talented new residents to our programs. It is also an imposing time for residency applicants, particularly this year after pandemic-shortened rotations and virtual residency interviews. Just as residencies want to match with outstanding students, applicants want to find the best programs. Although some students are simply looking for the right location for their families, many seek the highest quality training. With over 700 programs in America, how can medical students possibly discern which programs are best? Advising these students requires us to acknowledge how little we know about evaluating residency programs. Often, we simply consider subjective criteria like reputation and popularity, but is a program really better just because it attracts more applicants? To be more objective, we might consider the Accreditation Council for Graduate Medical Education's (ACGME) review process. Are the highest quality programs those that receive the fewest citations in the review process? Unfortunately, the accreditation process is not designed to measure program quality; it is designed to define and enforce a minimum standard, and historically, our minimum standard has been more permissive than rigorous. Is this by design? Have we hesitated to pursue a more demanding standard because we are afraid that too many residencies would miss the mark? If the accreditation process does not help us to find excellence, perhaps we can agree that the best residency programs are those that excel at helping residents achieve their potential. It seems logical that the best residencies produce the best graduates. If this is the case, we must confront the daunting task of evaluating graduate performance over the course of a career. About this, we know little. In the end, advising students about residency quality requires us to scrutinize both the attributes of a residency and the characteristics and accomplishments of its graduates.

In this issue of Family Medicine, two timely articles provide insight about this dichotomy. Drs Fugazzi and Cummings provide an overview of how the residency accreditation landscape has changed since the implementation of a Single Accreditation System (SAS) for programs previously accredited in the osteopathic and allopathic systems. ${ }^{1}$ Their paper focuses on the fate of 122 programs previously accredited in the osteopathic system, and describes how the SAS will influence the makeup of family medicine residencies for years to come. The ACGME Review Committee for Family Medicine is now undertaking a major revision of our program requirements, and for the first time, we are working to define one standard. This is good for family medicine and for the people served by our graduates. Fugazzi and Cummings also describe how the SAS process dealt with programs that could not adaptsomething we will likely confront again if we raise our accreditation standards to meet our country's changing health care needs.

In contrast, Dr Pereira and colleagues describe a sophisticated approach, undertaken by our Canadian colleagues, to assess the practice characteristics of residency graduates in the province of Ontario. ${ }^{2}$ Their study addressed

From the Family Medicine Residency Program (Dr Skariah), and Department of Family Medicine (Dr Saultz), Oregon Health and Science University, Portland, OR. 
practice location, population served, and several clinical quality indicators and correlated these characteristics with physician performance on the Canadian board certification exam. Notably, this study examined two core attributes of family medicine - continuity and comprehensiveness of care-using previously-validated measures and found that 59\% of graduates were providing continuity care and $72 \%$ were providing comprehensive care. A next step in this research could be to examine how graduates' practice patterns correlate with their residency experiences and to explore the utility of this method to evaluate residency programs.

Defining excellence for family medicine residencies in a way that includes comprehensiveness of graduate practice is both appealing and challenging. Students apply to family medicine residencies hoping to gain broad skills in the full scope of family medicine while meeting the specific needs of their communities. They seek to be personal and community physicians, providing the essential work that is needed to improve our country's health. Upcoming changes in the ACGME program requirements should require programs to address the comprehensive depth and breadth of family medicine as well as its core attributes. Flexibility in our requirements is only a virtue if we can agree what to be flexible about without compromising on core principles. Many of today's family medicine residencies exist in compromised settings where the prevailing scope of practice is much narrower than that desired by residency applicants. ${ }^{3,4}$ This needs to change. The health of America's small towns, underserved communities, and rural hospitals depends on our choices now. Comprehensive scope of care in every residency and comprehensive training for every graduate is achievable with the right support during and after training. ${ }^{5}$

It is time to stop settling for the easily achievable and aim for the ideal. Now is the time to raise the bar for family medicine residencies, because our applicants are looking for higher quality and our country needs better health care for the people we serve. If some programs cannot or will not meet this challenge, so be it. The potential for excellence lies within every family medicine resident. It is our job to help them reach it.

\section{References}

1. Fugazzi L, Cummings M. The AOA/ACGME single accreditation system and its immediate and future impact on Family Medicine. Fam Med. 2022;54(2):91-96.

2. Pereira J, Hogg W, Graves E, et al. Practice profiles and patterns of Ontario family medicine residents five years after residency examinations: an exploratory study. Fam Med. 2022;54(2):97-106

3. Peterson LE, Fang B, Puffer JC, Bazemore AW. Wide gap between preparation and scope of practice of early career family physicians. J Am Board Fam Med. 2018;31(2):181-182. doi:10.3122/jabfm.2018.02.170359

4. Eden AR, Barreto T, Hansen ER. Experiences of new family physicians finding jobs with obstetrical care in the USA. Fam Med Community Health. 2019;7(3):e000063. doi:10.1136/ fmch-2018-000063

5. Russell A, Fromewick J, Macdonald B, et al. Drivers of scope of practice in family medicine: a conceptual model. Ann Fam Med. 2021;19(3):217-223. doi:10.1370/afm.2669 